\section{US survey reveals deficits in women's health care}

Janice Hopkins Tanne, New York

A study of women's health in the United States by the Commonwealth Fund, a philanthropic organisation, has indicated worsening health care for poorer women and revealed widespread violence and abuse.

The study, conducted by a national polling organisation, was based on telephone interviews with 2850 women and 1500 men between May and November 1998, who were chosen as a cross section of the population, with an additional over sample of African American, Hispanic, and Asian American women.

Interviewees were asked about access to care, health knowledge and behaviour, violence, depression, use of hormone replacement therapy, and caregiving roles.

Results published last week showed that the number of non-

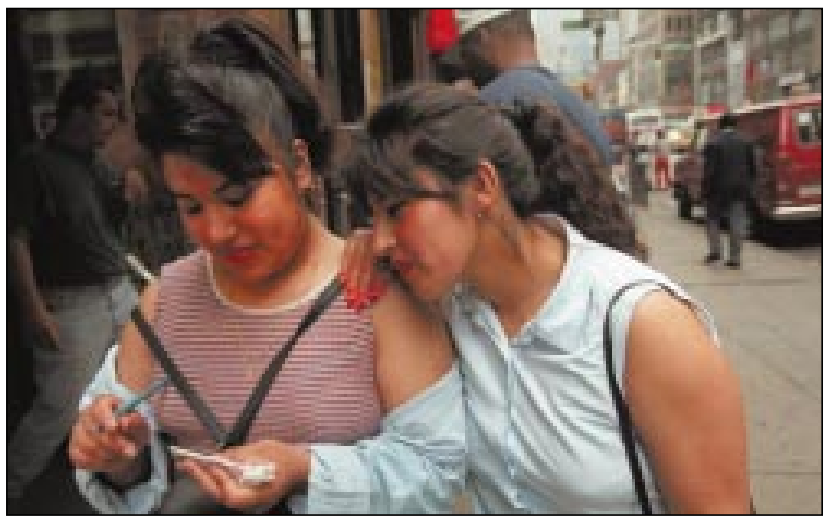

Many female workers may lose their health insurance if they lose their jobs

insured women of working age had increased from $14 \%$ to $18 \%$ since a comparable survey in 1993. In the lowest income category-under $\$ 16000(£ 10000)$ a year-35\% of women had no health insurance. The main reason seemed to be a drop in health insurance provided through the woman's job or through her husband's employment.

Only one half to two thirds of the women interviewed had received preventive care in the past year, including a physical examination, clinical breast examination, cervical smear, or cholesterol test, even though $76 \%$ of women were in managed care. This was about the same number as five years ago. Women on low incomes and those who did not have a university education were less likely to receive regular preventive care or advice on hormone replacement therapy.

Regardless of insurance coverage, $20 \%$ of women under the age of 65 reported problems in getting medical care they thought they needed, having access to a specialist, or getting a prescription filled because of cost.

The Commonwealth Fund is working with the National Committee for Quality Assurance, an accrediting organisation, to identify the health plans that include the best practices in women's health. Senator Patty Murray, Washington state, has recently introduced a bill in the US Senate that would require managed care plans to cover contraception, mammography, and screening for colon cancer, and to provide information about treatments such as hormone replacement therapy.

Violence and abuse were identified as major problems by the survey. Thirty nine per cent of women reported that they had experienced domestic abuse or violence, childhood physical or sexual abuse, or rape.

Health Concerns Across a Woman's Lifespan: The Commonwealth Fund 1998 Survey of Women's Health is publication number 332 of the Commonwealth Fund Commission on Women's Health. It is available free from the Commonwealth Fund, 1 East 75th Street, New York, NY 10021, USA, and is also posted on the fund's website: www.cmwf.org.

\section{Women with epilepsy are not getting pregnancy advice}

Vicki Madden, London

Women with epilepsy are not getting the advice they need on issues relating to contraception and pregnancy, according to a survey of women members of the British Epilepsy Association (Seizure 1999;8:135-9).

A total of 1855 women aged 16 or older with epilepsy returned questionnaires sent to 6000 women members of the association. Half of the women, aged between 16 and 55 claimed to have received no advice about possible interactions between their antiepileptic drug treatments and the methods of contraception they used.

Of the 189 women taking the oral contraceptive pill, only $43 \%$ had been given advice about the reduced effectiveness of the pill when it was taken together with enzyme inducing antiepileptic drugs, and $16 \%$ claimed to have received no information at all.
While nearly half $(47 \%)$ of those surveyed had children and $23 \%$ were planning to have children in the future, one third claimed to have received no advice about the effects of epilepsy on their pregnancy.

The teratogenicity of antiepileptic medication was discussed with only $15 \%$ of those women who planned to have children within the next two years. Prepregnancy counselling and the need for folic acid supplementation and extra monitoring during pregnancy was discussed with only a tiny minority $(5 \%)$ of the women.

Commenting on the findings of the survey, Dr Pamela Crawford, consultant neurologist at York District Hospital, said that women with epilepsy should aim to be taking the lowest possible dose of a single drug that will control their seizures

\section{Ashworth announces its reform plan}

Annabel Ferriman, parliamentary correspondent, BMJ

Ashworth Hospital, which was recommended for closure in January in a damning report (23 January, p 211), has produced an action plan to overcome its failings.

The Merseyside hospital, which has a personality disorder unit that houses some of England and Wales's most disturbed and dangerous patients, will receive $£ 5.7 \mathrm{~m}(\$ 9.1 \mathrm{~m})$ to finance the implementation of an elaborate new security plan.

The Fallon Report, published in January, made 39 recommendations concerning Ashworth and called for its closure, together with two other special hospitals, Rampton in Nottinghamshire and Broadmoor in Berkshire. The report recommended that they be replaced by a network of small, regional, secure units.

Frank Dobson, the secretary of state for health, rejected the recommendation that the hospital be closed and appointed a new chairman at Ashworth, Ian Pirnie, who was given the task of producing an action plan within four months.

Mr Pirnie, in his report to the secretary of state, says that "a commendable proportion" of the recommendations have already been implemented. These include banning children from visiting the hospital wards and screening patients' mail and telephone calls. Of the 16 members of staff at Ashworth who were criticised in the Fallon Report, only three are still working at the hospital.

Among the recommendations that have not yet been implemented are plans to introduce the searching of staff and a review of security. Mr Dobson has welcomed the Ashworth action plan. "The work to produce the action plan has already brought improvements," he said. "We now need to build on those improvements." 